\title{
Pengaruh Suhu Awal Media Pendingin Terhadap Kekerasan dan Kekuatan Impact pada Baja Karbon Medium yang Diperlakukan Quenching
}

\author{
Rendisetyo A. ${ }^{1}$, Wahono ${ }^{2}$, Duwi Leksono Edy ${ }^{3}$ \\ ${ }^{1,2,3}$ Program Studi S1 Pendidikan Teknik Mesin \\ 1,2,3 Jurusan Teknik Mesin Fakultas Teknik Universitas Negeri Malang \\ e-mail: Rendisetyo12@gmail.com ${ }^{1}$
}

\begin{abstract}
Abstrak: Tujuan penelitian ini adalah untuk mengetahui pengaruh suhu awal media pendingin terhadap kekerasan dan kekuatan impact pada baja medium yang diperlakukan quenching. Baja yang digunakan adalah S50C dengan media pendingin oli dengan viskositas 20w-40. Pendekatan penelitian yang digunakan dalam penelitian ini adalah kuantitatif, model penelitian pre-eksperimental dengan kategory one-group spesimen eksperimen and spesimen control. Variasi suhu awal media pendingin yang digunakan adalah $30^{\circ} \mathrm{C}, 35^{\circ} \mathrm{C}$, $45^{\circ} \mathrm{C}$ dan $55^{\circ} \mathrm{C}$. Hasil penelitian penelitian ini menunjukkan terdapat peningkatan nilai kekerasan disetai dengan meningkatnya suhu oli. Pada suhu $30^{\circ} \mathrm{C}$ memiliki nilai kekerasan 204,39 HVN dan ketangguhan 0,0618 Joule/mm, pada suhu $35^{\circ} \mathrm{C}$ nilai kekerasan menjadi $255,14 \mathrm{HVN}$ dan ketangguhan 0,0478 joule $/ \mathrm{mm}$, 450C memiliki nilai kekerasan 271,03 HVN dan ketangguhan 0,048 Joule/mm. Dan pada suhu 550C nilai kekerasan 234,11 HVN dan ketangguhan 0,0525 Joule/mm.
\end{abstract}

Kata kunci: Suhu oli, Kekerasan, Ketangguhan, Baja S50C, Quenching

\begin{abstract}
The porpose of this study was find out the effect of intial temperatur colling medium on harness and toughness of medium steel carbon with quenching prosess. The steel will be used is S50C and the cooling medium with value viscosity of 20-40. The research methods used is kuantitatif with pre-eksperiment design and one-group spesimen control and spesimen eksperimen category. The variation initial temperature colling medium used is $30^{\circ} \mathrm{C}, 35^{\circ} \mathrm{C}, 45^{\circ} \mathrm{C}$ dan $55^{\circ} \mathrm{C}$. The results of this study indicate there is an increase in the value of hardness in line with an increase in oil temperature. At a temperature of $30^{\circ} \mathrm{C}$ has a hardness value of 204.39 $\mathrm{HVN}$ and a toughness of 0.0618 Joules / $\mathrm{mm}$, at a temperature of $35^{\circ} \mathrm{C}$ a hardness value of $255.14 \mathrm{HVN}$ and a toughness of 0.0478 joules $/ \mathrm{mm}, 45^{\circ} \mathrm{C}$ has a hardness value of $271.03 \mathrm{HVN}$ and a toughness of 0.048 Joules / $\mathrm{mm}$. And at $55^{\circ} \mathrm{C}$ the value of hardness is $234.11 \mathrm{HVN}$ and the toughness is 0.0525 Joules $/ \mathrm{mm}$.
\end{abstract}

Keywords: temperature of oil, hardness, toughness, Steel S50C, Quenching.

Perkembangan teknologi terus meningkat seiring dengan perkembangan zaman. Dampak yang ditimbulkan dari perkembangan teknologi mengharuskan industri untuk menciptakan produk-produk yang tepat guna. Perkembangan mesin produksi, alat transportasi, alat pertanian dan berbagai alat pemesinan lainnya juga semakin pesat, dengan diikuti tingkat kualitas dan kuantitas hasil produksi. Untuk meningkatkan kualitas dan kuantitas hasil produksi dapat dilakukan dengan pemilihan material yang tepat. Penggunaan material dalam menentukan kualitas hasil produksi. Pemilihan material sebagai bahan produksi dilakukan dengan menentukan sifat yang dibutuhkan pada komponen tersebut. Terdapat berbagai material yang dapat digunakan sebagai bahan produksi komponen pemesinan salah satunya adalah baja.

Peran baja pada industri terus berkembang, karena memiliki sifat yang sesuai dengan kebutuhan dalam pembuatan komponen mesin. Sifat baja yang tidak dapat dibandingkan dengan material lain adalah kekerasan, kekuatan, ketangguhan dan keuletan yang baik. Kekerasan merupakan kemampuan baja untuk menahan deformasi plastis dan juga deformasi permanen (Dieter,1986:328). Tingkat kekerasan pada baja dapat ditingkatkan sesuai dengan keperluan bahan yang digunakan untuk material komponen mesin. Peningkatan nilai kekerasan pada baja dapat dilakukan dengan dua cara yaitu dengan perlakuan panas (heat treatment) dan deformasi plastis. Peningkatan kekerasan baja dengan perlakuan panas dapat dilakukan dengan cara

Pengaruh Suhu Awal Media Pendingin Terhadap Kekerasan dan Kekuatan Impact ........ 
memanaskan baja pada suhu austenit lalu ditahan beberapa saat dan didinginkan dengan cepat. Pendinginan cepat akan merubah struktur austenit menjadi struktur martensit yang memiliki sifat yang keras dan getas.

Struktur martensit akan menyebabkan nilai kekerasan semakin meningkat, akan tetapi nilai kekuatan impact benda juga akan menurun(Daryanto,2010: 250). Selain kandungan karbon pada baja, terdapat beberapa faktor yang mempengaruhi jumlah martensit yang dihasilkan dalam perlakuan panas antara lain (1) Suhu pemanasan, (2) holding time, dan (3) media pendingin.

Struktur martensit pada baja akan terbentuk jika laju pendinginan mencapai suhu kritis. Terdapat banyak jenis medialpendinginllyanglseringlldigunakan untuk proses quenching antarallainllair, oli, dan udara.lMedia pendingin menjadi salah satu faktor penting dalam proses quenching dimana perbedaan jenis media pendingin akan sangat mempengaruhi dari laju pendinginan (Zakharov,1986:73). Suhu pendinginan krisis ini sangat bergantung pada kadar karbon baja. seperti yang telah dijelaskan oleh Zakharov (1986) bahwa semakin tinggi kadar karbon yang terkandung dalam baja maka tingkat pendinginan kritis akan semakin menurun. Untuk mendapatkan struktur martensit pada baja, maka baja harus didinginkan hingga mencapai suhu antara ( $3000 \mathrm{C}-2000 \mathrm{C}$ ).

Kecepatan media pendingin tergantung dari beberapa faktor antara lain perbedaan titik didih, viskositas, konduktivitas thermal. Untuk media pendingin air kecepatan pendingin yang dapat dicapai adalah 270 0C/s sedangkan oli memiliki kecepatan pendinginan 500C/s (Zakharov, 1986:75).

Wijaya (2018) telah melakukan penelitian tentang pengaruh air tersikulasi terhadap sifat mekanis baja AISI 1045. BajalAISIll1045 merupakanlbajallkarbon sedang yang memiliki kadar karbon 0,45\%. Penelitian tersebut menggunakan tiga jenis variasi debit air, yaitu Q1 $(0 \mathrm{~m} / \mathrm{s})$; Q2 $(0,77381 \mathrm{~m} / \mathrm{s})$ dan Q3 $(0,95238 \mathrm{~m} / \mathrm{s})$. Yang kekerasan yang dicapai Q1 adalah 78,33 HRB, Q2 yaitu 82,89 HRB dan Q3 adalah 87,11 HRB. Dari penelitian diatas dapat diketahui bahwa semakin besar nilai debit air maka kekerasan juga semakin meningkat. Hal ini terjadi karena pada saat pencelupan benda kerja pada media pendingin, permukaan media pendingin dan sekitarnya akan menguap dan menyelimuti benda kerja sehingga kecepatan pendinginan akan menurun. Dengan pencelupan benda kerja kedalam air yang mengalir, penguapan pada media pendingin dapat dikurangi yang mengakibatkan jumlah uap yang menyelimuti benda kerja akan menurun dan kecepatan pendinginan akan meningkat. Dengan meningkatnya kecepatan pendinginan menghasilkan persentase struktur martensit yang semakin besar.

Penelitian lain juga dilakukan oleh Hidayat (2016) dengan memvariasi suhu media pendingin air dengan variasi suhu 200C, 500C dan 800C pada baja karbon S45C. Yang hasil kekerasan pada setiap suhu secara berturut-turut adalah 1698,875lHVN,1764,075 HVN,ldan 583,05 HVN. Dari penelitian yag dilakukan oleh Hidayat dapat diketahui bahwa suhu awal pada media pendingin air mempengaruhi tingkat kekerasan benda. Dengan menaikkan suhu awal media pendingin akan meyebabkan media pendingin lebih cepat mencapai titik didih, sehingga penguapan disekitar media pendingin juga meningkat. Hal ini akan menyebabkan lapisan uap pada benda kerja juga akan bertambah dan kecepatan pendingan juga akan melambat, sehingga jumlah martensit yang terbentuk juga akan berkurang.

Zakharov (1986) menyebutkan dalam bukunya bahwa dengan melakukan pre-heating pada media pendingin air akan melambatkan kecepatan pendinginan, akan tetapi efek yang dihasilkan juga sangat kecil. Sedangkan untuk pemanasan pada media pendingin oli akan mempengaruhi viskositasnya dan akan meningkatkan kecepatan pendinginannya. Dari pernyataan Zakharov inilah peneliti penasaran apakah benar bahwa oli jika dipanaskan akan memperngaruhi kecepatan pendinginan dan mempengaruhi sifat baja pada proses perlakuan panas?. sehingga peneliti ingin melakukan penelitian mengenai pengaruh suhu awal media pendingin terhadap kekerasan dan kekuatan impact pada baja sebagai bentuk pembuktian dari pernyataan Zakharov tersebut.

\section{METODE}

Penelitian ini menggunakan desain penelitian pre-eksperimental dengan kategori One-Group Spesimen Eksperimen and Spesimen Control yaitu bentuk penelitian yang terdapat pengukuran Spesimen Control sebelum diberi perlakuan (treatment) kemudian diukur kembali dan dibandingkan hasil. Adapun dasar pemilihan desain penelitian tersebut adalah tingkat akurasi yang dihasilkan dari desain penelitian one-group spesimen control and spesimen eksperimen lebih tinggi. Selain itu dengan desain penelitian tersebut diharapkan dapat mengetahui adanya peningkatan atau penurunan nilai kekerasan setelah perlakuan dan sebelum perlakuan. Bentuk paradigma One-Group Spesimen Control And Spesimen Eksperimen sebagai berikut: 


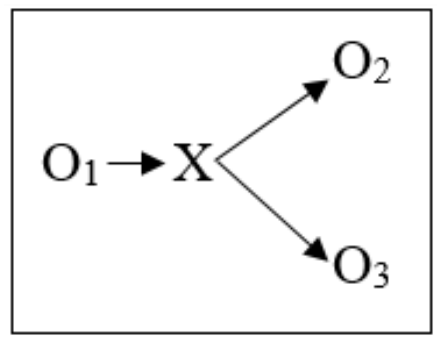

Gambar 1. Desain penelitian

Variabel dalam penelitian ini adalah suhu awal media pendingin oli (X) sedangkan untuk variabel terikatnya adalah nilai kekerasan $\left(\mathrm{O}_{2}\right)$ dan kekuatan impact $\left(\mathrm{O}_{3}\right)$ baja S50C. variabel kontrol dalam penelitian ini adalah temperatur pemanasan yaitu $850^{\circ} \mathrm{C}$, holding time selama 30 menit, status alat uji yang digunakan, media pendingin oli $20 \mathrm{~W}-40$ dan waktu pendinginan 30 menit. Sampel penelitian yang digunakan adalah baja S50C dengan kandungan 0,5 \% C, 0,3\% Si dan 0,7 Mn dengan ukuran seperti dibawah ini:

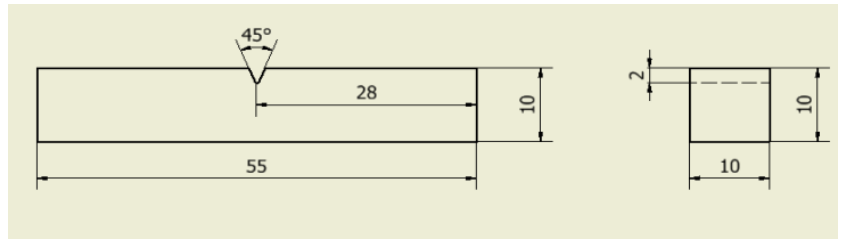

Gambar 2 Ukuran Spesimen

Teknik pengumpulan data yang digunakan adalah dokumentasi dan observasi, untuk uji kekerasan micro vickers dilakukan di laboratorium pemesinan Universitas negeri Malang dan untuk uji impact dilakukan di Laboratorium Teknik Mesin Institut Teknologi Nasional Malang, dengan Instrumen sebagai berikut:

\begin{tabular}{clcccccc}
\hline \multirow{2}{*}{ No } & \multicolumn{2}{c}{ Spesimen } & \multicolumn{3}{c}{ Nilai Kekerasan } & \multicolumn{2}{c}{ Nilai Ketangguhan } \\
\cline { 3 - 8 } & & 1 & 2 & 3 & 4 & 5 & 6 \\
\hline $\mathbf{l}$ & Raw Material & $\mathrm{X}_{11}$ & $\mathrm{X}_{12}$ & $\mathrm{X}_{13}$ & $\mathrm{X}_{14}$ & $\mathrm{X}_{15}$ & $\mathrm{X}_{16}$ \\
$\mathbf{2}$ & Quenching dengan suhu oli $30^{\circ} \mathrm{C}$ & $\mathrm{X}_{21}$ & $\mathrm{X}_{22}$ & $\mathrm{X}_{23}$ & $\mathrm{X}_{24}$ & $\mathrm{X}_{25}$ & $\mathrm{X}_{26}$ \\
$\mathbf{3}$ & Quenching dengan suhu oli $35^{\circ} \mathrm{C}$ & $\mathrm{X}_{31}$ & $\mathrm{X}_{32}$ & $\mathrm{X}_{33}$ & $\mathrm{X}_{34}$ & $\mathrm{X}_{35}$ & $\mathrm{X}_{36}$ \\
$\mathbf{4}$ & Quenching dengan suhu oli $45^{\circ} \mathrm{C}$ & $\mathrm{X}_{41}$ & $\mathrm{X}_{42}$ & $\mathrm{X}_{43}$ & $\mathrm{X}_{44}$ & $\mathrm{X}_{45}$ & $\mathrm{X}_{46}$ \\
$\mathbf{5}$ & Quenching dengan suhu oli 55 $55^{\circ} \mathrm{C}$ & $\mathrm{X}_{51}$ & $\mathrm{X}_{52}$ & $\mathrm{X}_{53}$ & $\mathrm{X}_{54}$ & $\mathrm{X}_{55}$ & $\mathrm{X}_{56}$ \\
\hline
\end{tabular}

Gambar 3 Instrumen Penelitian

Prosedur pengumpulan data dilakukan dengan memanaskan baja $\mathrm{S} 50 \mathrm{C}$ pada suhu $850^{\circ} \mathrm{C}$ selama 30 menit kemudia didinginkan dengan cepat menggunakan media pendingin oli dengan suhu awal $30^{\circ} \mathrm{C}, 35^{\circ} \mathrm{C}, 45^{\circ} \mathrm{C}$ dan $55^{\circ} \mathrm{C}$. Hasil proses tersebut kemudian dibersihkan untuk selanjutnya diuji kekerasan dan kekuatan impactnya. Hasil dari pengujian tersebut kemudian di analisis menggunakan analisis one way ANOVA.

\section{HASIL}

Data yang dihasilkan dari penelitian ini adalah berupa nilai kekerasan dan nilai ketangguhan baja sebelum dan setelah mengalami perlakuan pemanasan pada suhu $850^{\circ} \mathrm{C}$ selama 30 menit yang kemudian didinginkan dengan cepat menggunakan media pendingin oli viskositas $20 \mathrm{~W}-40$ dengan suhu awal $30^{\circ} \mathrm{C}, 35^{\circ} \mathrm{C}, 45^{\circ} \mathrm{C}$ dab $55^{\circ} \mathrm{C}$. Berikut merupakan hasil pengujian kekerasan micro vickers setelah dan sebelum perlakuan quenching:

Pengaruh Suhu Awal Media Pendingin Terhadap Kekerasan dan Kekuatan Impact 


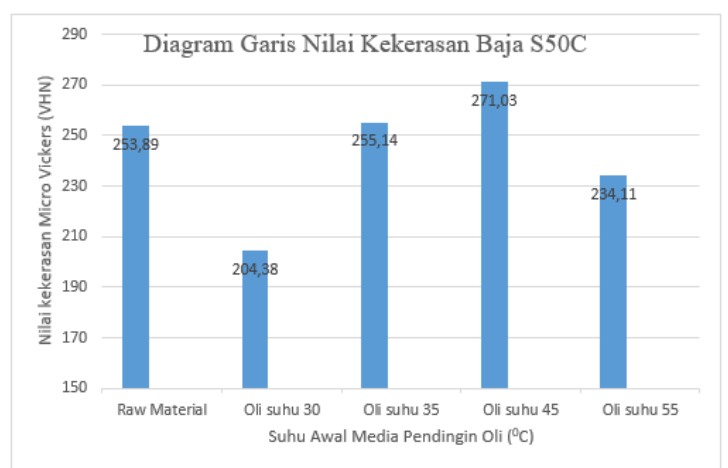

Gambar 4 Hasil Nilai Kekerasan Micro Vickers

Dari gambar diatas dapat diketahui bahwa nilai kekerasan terendah adalah pada suhu $30^{\circ} \mathrm{C}$ dengan nilai kekerasan 204,38 HV. Pada suhu $35^{\circ} \mathrm{C}$ dan $45^{\circ} \mathrm{C}$ mengalami kenaikan kekerasan menjadi $255,14 \mathrm{HV}$ dan $271,03 \mathrm{HV}$ yang kemudian mengalami penurunan pada suhu $55^{\circ} \mathrm{C}$ menjadi 244,11 HV. Adapun hasil uji ketangguhan baja setelah perlakuan quenching menggunakan oli dengan viskositas $20 \mathrm{~W}-40$ pada suhu $30^{\circ} \mathrm{C}, 35^{\circ} \mathrm{C}, 45^{\circ} \mathrm{C}$, dan $55^{\circ} \mathrm{C}$ adalah sebagai berikut:

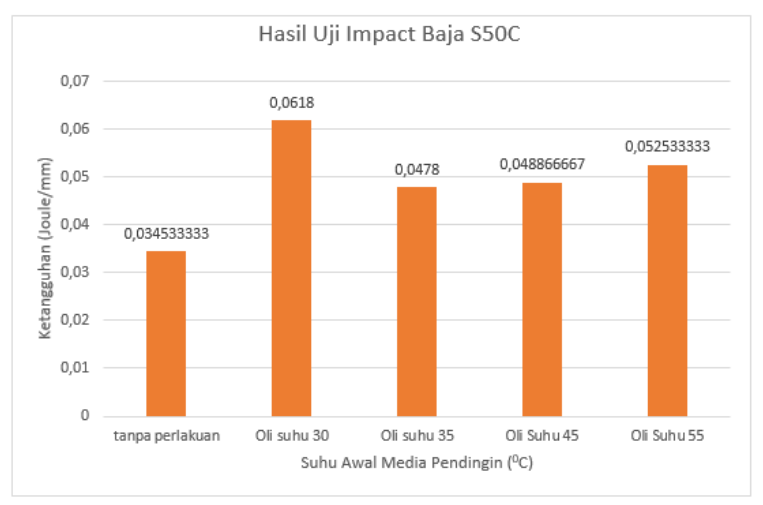

Gambar 5 Hasil Uji Impact

Dari tabel diatas dapat diketahui bahwa nilai kekuatan impact tertinggi adalah pada suhu $30^{\circ} \mathrm{C}$ yaitu pada angka 0,0618 Joule/mm yang artinya bahwa pada suhu ini sifat baja paling ulet. Sedangkan nilai impact terendah adalah suhu $35^{0} \mathrm{C}$ yaitu pada angka 0,0478 Joule/mm. Hasil dari kedua pengujian tersebut kemudian dianalisis menggunakan One-Way ANOVA. Yang hasilnya adalah sebagai berikut:

\begin{tabular}{l|r|r|r|r|r}
\hline \multicolumn{7}{c}{ ANOVA } \\
\hline nilai kekerasan & \multicolumn{1}{c}{} & & \\
\hline & Sum of Squares & \multicolumn{1}{c|}{ df } & Mean Square & \multicolumn{1}{c}{ F } & \multicolumn{1}{c}{ Sig. } \\
\hline Between Groups & 22408,036 & 3 & 7469,345 & 14,256 &, 000 \\
\hline Within Groups & 16766,760 & 32 & 523,961 & & \\
\hline Total & 39174,796 & 35 & & & \\
\hline
\end{tabular}

Gambar 6 Hasil Uji One Way ANOVA Data Kekerasan

Dari hasil uji One Way ANOVA diatas diketahui bahwa nilai signifikasi adalah 0,00 yang berarti lebih kecil dari 0,05, dan nilai $F_{\text {hitung }}$ adalah 14,256 yang berarti lebih besar dari $F_{\text {tabel }}$ yaitu 2,90. Dari kedua pernyataan diatas, dapat diartikan bahwa suhu awal media pendingin berpengaruh secara signifikan terhadap nilai kekerasan pada baja S50C setelah proses quenching. Selanjutnya adalah Analisis statistik data ketangguhan, yang hasilnya adalah sebagai berikut: 


\begin{tabular}{|c|c|c|c|c|c|}
\hline \multicolumn{6}{|c|}{ ANOVA } \\
\hline \multicolumn{6}{|l|}{ Ketangguhan } \\
\hline & Sum of Squares & df & Mean Square & $\mathrm{F}$ & Sig. \\
\hline Between Groups &, 000 & 3 &, 000 &, 221 & 879 \\
\hline Within Groups & .004 & 8 & 001 & & \\
\hline Total &, 005 & 11 & & & \\
\hline
\end{tabular}

Gambar 7 Hasil Uji One Way ANOVA Data Ketangguhan

Dari hasil uji One Way ANOVA diatas dapat diketahui bahwa nilai signifikasi untuk data ketangguhan adalah 0,0879 yang berarti lebih besar dari 0,05. Sehingga dapat diartikan bahwa tidak ada pengaruh yang signifikan suhu awal media pendingin oli terhadap nilai ketangguhan baja S50C setalah proses quenching.

\section{PEMBAHASAN}

\section{Pengaruh Suhu Awal Media Pendingin Oli terhadap Kekerasan Baja S50C}

Merujuk pada Gambar 4 dapat diketahui bahwa nilai kekerasan pada raw material baja S50C memiliki nilai $253,89 \mathrm{HV}$ dan mengalami penurunan pada pendinginan menggunakan media pendingin oli 20W-40 dengan suhu awal 300C menjadi 204,38 HV. hal ini dapat terjadi karena saat pemanasan baja tidak dilindungi oleh arang sehingga ada kemungkinan bahwa baja mengalami dekarburasi. Dekarburasi menurut Zakharov (1986) adalah proses reaksi baja pada lingkungan sekitarnya, pada kasus ini adalah oksigen $(\mathrm{O} 2)$, sehingga kandungan karbon pada baja akan berkurang yang menghasilkan nilai kekerasan pada baja juga akan menurun.

Pada grafik selanjutnya adalah pendinginan menggunakan media pendingin oli dengan suhu awal 350C dan 450C yang mempunyai nilai kekerasan yang meningkat dari suhu 300C. Hal ini dapat terjadi karena dengan melakukan pre-heating pada media pendingin oli akan menurunkan viskositasnya, yang mengakibatkan pada saat proses pendinginan oli dengan viskositas rendah lebih mudah untuk kontak dengan permukaan baja sehingga pendinginan dapat terjadi lebih cepat. Begitu juga sebaliknya, media pendingin oli dengan viskositas tinggi akan mempersulit media pendingin untuk melakukan kontak dengan benda kerja, sehingga proses pendinginan terjadi lebih lambat.

Pernyataan diatas sesuai dengan teori Zakharov (1986) bahwa melakukan pre-heating pada media pendingin oli akan mempengaruhi viskositasnya dan akan meningkatkan kecepatan pendinginannya. Sebagaimana yang telah jelaskan oleh Zakharov (1986) bahwa pemanasan akan memperngaruhi viskositas media pendingin oli, hal ini telah dibuktikan oleh Lumbantoruan (2016) yang meneliti tentang "Pengaruh Suhu terhadap Viskositas Minyak Pelumas (Oli)" yang hasilnya adalah sebagai berikut:

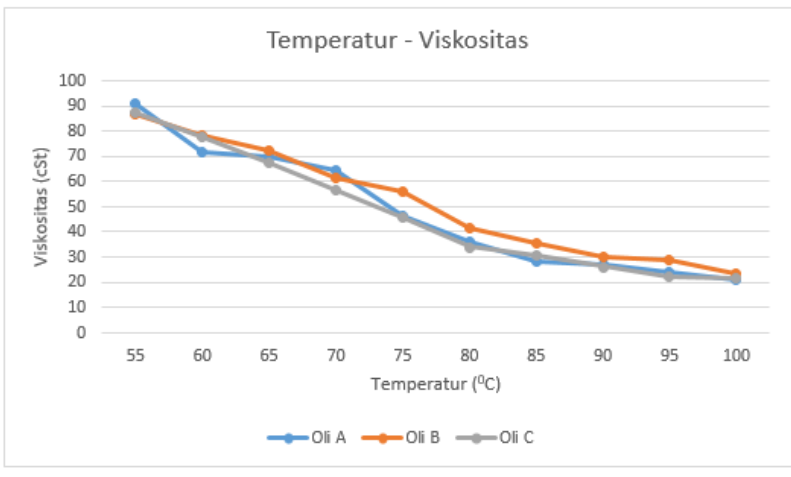

Gambar 8 Hubungan Viskositas dan Temperatur

Pengaruh Suhu Awal Media Pendingin Terhadap Kekerasan dan Kekuatan Impact 
Dari Gambar 8 dapat diketahui bahwa terdapat 3 jenis oli dengan SAE yang sama. Pada saat oli dipanasakan dengan temperatur tertentu maka viskositas oli juga akan berubah, dimana semakin tinggi suhu pemanasan pada oli maka viskositas oli akan semakin menurun atau oli akan semakin encer. Dengan viskositas yang rendah tersebut pada saat pendinginan akan mempermudah media pendingin oli untuk melakukan kontak dengan baja yang dipanaskan sehingga dapat mempercepat laju pendinginan. hal ini sejalan dengan penelitian yang dilakukan oleh Murjito (2019) tentang “ Analisa Variasi Viscositas Pelumas pada Proses Quenching terhadap Sifat Mekanik Baja Aisi 1045 “ yang hasilnya adalah sebagai berikut:

Dari hasil penelitian yang dilakukan oleh Murjito (2019) diatas dapat disimpulkan bahwa semakin tinggi nilai viskositas oli maka kekerasan akan semakin menurun, begitu juga sebaliknya semakin rendah viskositas oli maka kekerasan baja akan semakin meningkat. Dengan kedua penelitian terdahulu tersebut dirasa cukup dalam membuktikan bahwa temperatur pemanasan pada media pendingin oli akan mempengaruhi nilai kecepatan pendinginannya.

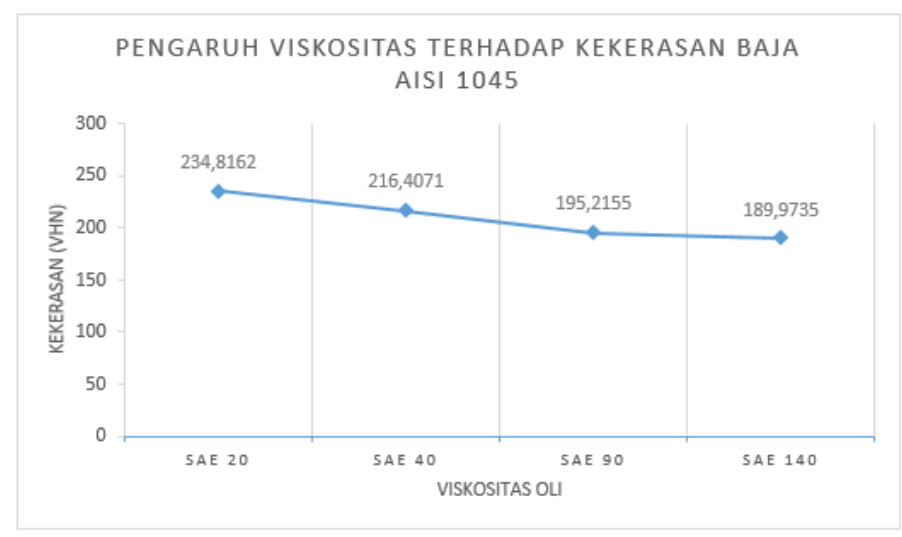

Gambar 9 Hubungan Viskositas dan Nilai Kekerasan Baja

Pada Gambar 9 diketahui bahwa kekerasan pada suhu $55^{\circ} \mathrm{C}$ menurun dari suhu sebelumnya yaitu suhu $45^{\circ} \mathrm{C}$, yang nilainya adalah 271,03 VHN menjadi 234,11 VHN. Hal ini dapat terjadi karena suhu oli yang terlalu tinggi ada kemungkinan bahwa viskositas oli sudah mencapai maksimum yang dapat dicapai, sehingga pada saat pendinginan oli tidak dapat mendinginkan baja dengan baik. Pernyataan tersebut sesuai dengan yang telah dijelaskan oleh Sucahyoaji (2016) tentang grafik temperatur dan viskositas seperti dibawah ini:

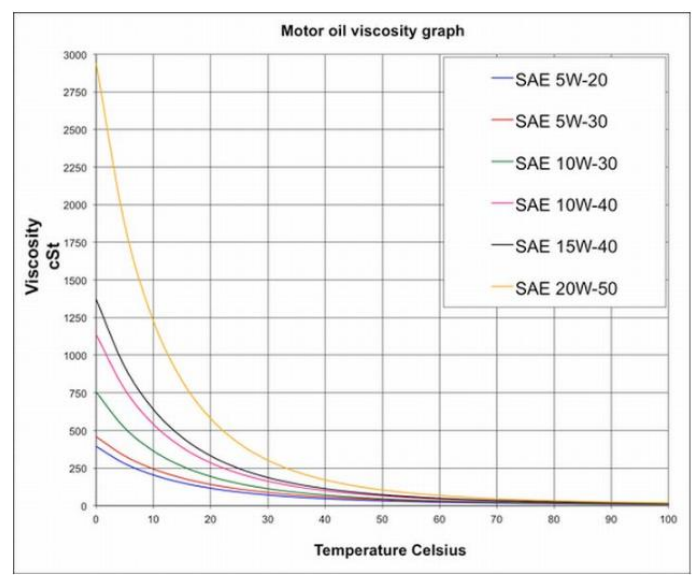

Gambar 10. Hubungan Viskositas Oli Motor dan Temperatur 
Dari gambar diatas dapat diketahui bahwa viskositas pada suhu $45^{\circ} \mathrm{C}$ dan $55^{\circ} \mathrm{C}$ mengalami penurunan yang sangat sedikit dan hampir segaris dengan suhu yang lebih tinggi. Sehingga terdapat kemungkinan bahwa viskositas oli telah mencapai tingkat maksimum untuk oli dengan viskositas 20W-40 sehingga oli todak dapat mendinginkan baja dengan baik.

\section{Pengaruh Suhu Awal Media Pendingin Oli terhadap Ketangguhan Baja S50C}

Dari Gambar 5 dapat diketahui grafik kenaikan dan penurunan nilai ketangguhan untuk baja S50C setelah mengalami proses quenching dengan pemanasan $8500 \mathrm{C}$ selama 30 menit kemudian didingin dengan cepat pada media pendingin oli dengan suhu awal yang 300C, 350C,450C, dan 550C. Dalam Gambar 5 dapat diketahui bahwa nilai ketangguhan relatif menurun yang mempunyai arti bahwa bahan semakin getas. Nilai tertinggi dari keempat perlakuan adalah pada pencelupan dengan menggunakan oli yang mempunyai suhu 300C dengan nilai ketangguhan (HI) 0,0618 Joule/mm yang kemudian menurun pada pendinginan dengan menggunakan oli dengan suhu awal 350C dengan nilai HI ada 0,0478 Joule/mm. Nilai HI mengalami kenaikan lagi pada suhu 450C dan 550C dengan nilai secara berurutan 0,04886 Joule/mm dan 0,0525 Joule/mm.

Dari uraian diatas dapat ditarik kesimpulan bahwa terdapat pengaruh suhu awal media pendingin terhadap nilai ketangguhan dalam baja, meski efek yang dihasilkan sangatlah sedikit (tidak signifikan). Hal ini dapat diketahui dari perbedaan nilai HI antar suhu yang memiliki perbedaan yang sangat sedikit.

Umumnya pada perlakuan panas apabila pembentukan austenite semakin banyak (yang dalam hal ini dipengaruhi oleh faktor temperature pemanasan dan waktu holding time) maka jumlah martensit juga akan semakin banyak persentasenya jika didinginkan dengan cepat. Hal ini akan mempengaruhi hasil kekuatan impact pada baja yang telah diperlakukan quenching. Selain tergantung pada waktu pemanasan salah satu faktor yang dapat mempengaruhi adalah kadar karbon dalam baja. Semakin besar kadar karbon pada baja maka akan menghasilkan baja yang semakin getas dan semakin rendah kadar karbon pada baja maka akan semakin ulet sifat baja. Pada temperatur pendinginan yang juga merupakan faktor kunci dari pembentukan martensite dimana pada pendinginan cepat akan menghasilkan struktur martensite yang lebih banyak dan membuat sifat baja akan semakin getas.

\section{PENUTUP}

Dari hasil penelitian yang telah dijelaskan pada bab sebelumnya, kesimpulan yang diperoleh dalam penelitian ini adalah sebagai berikut :(1)Terdapat pengaruh suhu awal media pendingin terhadap kekerasan baja S50C setelah mengalami proses quenching dengan menggunakan media pendingin oli. Nilai kekerasan akan cenderung semakin meningkat dengan meningkatnya suhu media pendingin oli. Nilai kekerasan tertinggi adalah quenching dengan menggunakan suhu awal media pendingin oli pada suhu 450C, yaitu 271,03 VHN. Sedangkan nilai kekerasan terendah adalah pada quenching menggunakan media pendingin oli dengan suhu awal 300C yaitu 204,38 VHN. (2)Tidak terdapat pengaruh yang signifikan suhu awal media pendingin terhadap nilai ketangguhan baja S50C setelah mengalami proses quenching menggunakan media pendingin oli. Nilai ketangguhan akan cenderung menurun dengan meningkatnya suhu akan tetapi peningkatan yang dihasilkan sangat sedikit. Nilai ketangguhan pada suhu awal media pendingin oli 300C, 350C, 450C dan 550C secara berurutan adalah 0,0618 Joule/mm2, 0,0478 Joule/mm2, 0,489 Joule/mm2, dan 0,0525 Joule/mm2. (3)Terdapat hubungan antara nilai kekerasan dan ketangguhan yaitu semakin tinggi nilai kekerasan maka nilai ketangguhan akan cenderung menurun. Begitu juga sebaliknya semakin rendah nilai kekerasan maka nilai ketangguhan juga akan cenderung naik.

\section{DAFTAR RUJUKAN}

Daryanto. 2010. Proses Pengolahan Besi dan baja ( Ilmu Metalurgi ). Bandung: Satu Nusa

Dieter. Goerge E. 1996. Metalurgi Mekanik. Terjemahan. Ir. Ny. Sriati Djaprie, M.E, M. Met. Jakarta: Penerbit Erlangga.1986.

Hidayat, Taufik, Priyagung Hartono, Sujatmiko.2016. Analisa Pengaruh Suhu Pada Media Pendingin Terhadap Sifat Mekanis (Kekerasan) Baja S45c Pada Proses Hardening. Jurnal Teknik Mesin, 6(2) 31-35

Lumbantoruan, Parmin \& Erislah Yulianti. 2016. Pengaruh Suhu terhadap Viskositas Minyak Pelumas (Oli). Sainmatika, 13 (2), 26-34

Murjito, dkk. 2019. Analisa Variasi Viscositas Pelumas Pada Proses Quenching Terhadap Sifat Mekanik Baja Aisi 1045. Seminar Nasional Teknologi dan Rekayasa (SENTRA) 2019. ISSN 2527-6042

Wijaya, Rahmad Satria. 2018. Pengaruh Media Air Yang Tersirkulasi Pada Proses Quenching Terhadap Kekerasan Dan Strukur Mikro Baja Aisi 1045. Lampung: Universitas Bandar Lampung.

Zakharov, B. 1986. Heat Treatment of Metals. Moscow: Peace Publishers

Pengaruh Suhu Awal Media Pendingin Terhadap Kekerasan dan Kekuatan Impact ........ 